\title{
Healthcare resource utilization and cost among patients with type 1 diabetes in the United States
}

\author{
Jason C Simeone, MS, PhD; Surbhi Shah, PhD; Michael L Ganz, MS, PhD; Sean Sullivan, PhD; Anne Koralova, PhD; \\ Jackie LeGrand, MPP; and Jesse Bushman, MA
}

\section{What is already known about this subject}

- Type 1 diabetes mellitus (T1DM) imposes a substantial economic burden (e.g., higher medical costs in treating long-term complications that cause morbidity and mortality).

- Although published studies have reported the economic burden of diabetes, most combined both types of diabetes (i.e., T1DM and type 2 diabetes mellitus [T2DM]) or provided estimates for T2DM only.

- Older cost estimates may not reflect current costs of care due to changes in care patterns (e.g., increasing use of insulin pumps and continuous glucose monitors).

\begin{abstract}
BACKGROUND: Approximately $5 \%-10 \%$ of patients with diabetes are diagnosed with type 1 diabetes mellitus (T1DM), the incidence and prevalence of which is projected to increase through 2050. Despite this, T1DM-related health care resource utilization (HCRU) and economic burden in the United States have not been adequately assessed, since previous studies used various cost definitions and underlying methods to examine these outcomes.
\end{abstract}

OBJECTIVE: To assess HCRU and costs incurred by patients with T1DM in the United States.

\section{What this study adds}

- The results of this retrospective realworld cohort study provide important, current insights into the health care resource utilization (HCRU) and costs incurred by pediatric and adult patients with T1DM.

- This study is unique in that it uses 3 large, national databases from disparate sources (administrative claims, electronic medical records [EMR], and patients with linked claims and EMR data) to generate robust estimates of health care resource use and costs associated with T1DM in the United States.

- During the follow-up period, total all-cause and diabetes-related costs ranged from $\$ 1,482$ to $\$ 1,522$ and $\$ 733$ to $\$ 780$ per patient per month, respectively; monthy pharmacy costs accounted for the majority of total diabetes-related costs across databases.

METHODS: This retrospective cohort study used IBM Watson MarketScan data from 2011 to 2015 and Optum's electronic medical record (EMR) and integrated data (i.e., linked EMR and administrative claims data) from 2011 to 2016. Included patients had $\geq 1$ T1DM diagnosis (the earliest diagnosis date was designated as the index date), were continuously enrolled for $\geq 6$ months during their pre-index baseline periods, and had $\geq 1$ pharmacy claim for insulin or an insulin pump within \pm 90 days of the index date. Baseline demographic and clinical characteristics were summarized descriptively. Average monthly HCRU and costs per patient per month (PPPM) paid by the health plan and

\author{
Author affiliations \\ Jason C Simeone, MS, PhD; Surbhi Shah, \\ PhD; and Michael L Ganz, MS, PhD, Evidera, \\ Waltham, MA. Sean Sullivan, PhD, and Anne \\ Koralova, PhD, The Leona M. and Harry B. \\ Helmsley Charitable Trust, New York, NY. \\ Jackie LeGrand, MPP, and Jesse Bushman, \\ MA, JDRF, Washington, DC.
}

AUTHOR CORRESPONDENCE: Jason C Simeone, 781.960.0274, jason.simeone@evidera.com patient were assessed. Costs were adjusted for inflation to 2018 U.S. dollars.

RESULTS: We identified 181,423 patients with T1DM who met the selection criteria in MarketScan, 84,759 in the Optum EMR, and 8,948 in the Optum integrated databases. Most patients were male (range across databases: $52.6 \%-53.1 \%$ ), relatively young (medians: 33-35 years, overall range: 0-100 years), and had a Charlson Comorbidity Index score of 1 (69.2\%-73.0\%) across all databases. Total all-cause and diabetes-related costs ranged from $\$ 1,482$ to $\$ 1,522$ and $\$ 733$ to $\$ 780$ PPPM, respectively, during the followup period. Pharmacy costs contributed most 
to the total cost of care, accounting for $55.3 \%$ (\$431) to $61.1 \%$ (\$448) of total diabetes-related costs. On an annualized basis, patients had an average of 0.2-0.9 all-cause hospitalizations and 0.1-0.3 diabetesrelated hospitalizations during follow-up. The median costs per diabetes-related hospitalization ranged from $\$ 6,548$ to $\$ 8,439$, accounting for $4 \%-7 \%$ of total monthly diabetes-related costs. Patients had an average of 0.4-0.5 all-cause and 0.1-0.2 diabetes-related emergency department (ED) visits annually; the median costs of ED visits were $\$ 972-\$ 1,499$, contributing about $2 \%$ of monthly diabetes-related costs during follow-up.

CONCLUSIONS: In this large, retrospective, observational study of pediatric and adult patients with T1DM, diabetes-related costs totaled nearly $\$ 800$ per month. Pharmacy costs contributed to over half of diabetes-related costs, indicating the substantial economic burden associated with the treatment of T1DM. Additional research is needed to determine risk factors associated with costly events (e.g., hospitalizations and ED visits) and indirect costs associated with T1DM.

Type 1 diabetes mellitus (T1DM) is an endocrine disorder characterized by a deficiency of insulin due to autoimmune destruction of pancreatic beta cells; this results in hyperglycemia and potential complications such as ketoacidosis, cardiovascular disease, nephropathy, and retinopathy. Globally, T1DM accounts for approximately 5\%-10\% of all diabetes. ${ }^{2}$ According to the Centers for Disease Control and Prevention, approximately 1.6 million people have T1DM, including about 187,000 children and adolescents in the United States. ${ }^{3}$ Projections of T1DM in the United States through 2050 show a linear increase in incidence over the next 30 years, ${ }^{4}$ thus, its prevalence is projected to increase 3 -fold by $2050 .{ }^{4}$

The annual average health expenditure per capita for patients with diabetes in the United States is nearly 2.3 times higher than that of the general population. ${ }^{5}$ Furthermore, the overall lifetime economic burden per patient diagnosed with T1DM is greater than the lifetime costs associated with care for type 2 diabetes mellitus (T2DM) because of higher medical costs for treating longterm complications that cause morbidity, mortality, and lost productivity. ${ }^{5-8}$ In a study that used data from the HealthCore Integrated Research Database between 2006 and 2014, Willey et al. (2018) found that the projected direct all-cause medical costs incurred by patients with T1DM in 2014 were $\$ 27.8$ billion, and projected diabetes-related costs were $\$ 10$ billion, ${ }^{8}$ with increased hospitalizations, use of outpatient services, and pharmacy prescription costs as the largest drivers of costs. Similarly, in 2010, Tao et al. found that hospital inpatient visits, prescription drugs, and medical supplies accounted for more than $75 \%$ of the yearly costs attributable to T1DM from 1999 to 2005. ${ }^{9}$

Although several published studies have reported on the economic burden of diabetes, most combine both types of diabetes (i.e., T1DM and T2DM) or provide estimates for T2DM only, and cost estimates from older studies may not reflect more recent changes in T1DM management, including an increased use of insulin pumps and continuous glucose monitors (CGM). Furthermore, there are variations in cost estimates because of differing definitions and underlying methods. Thus, the purpose of this study was to assess health care resource utilization (HCRU) and costs incurred by patients with T1DM in the United States, using multiple large sources of real-world data, including administrative claims and electronic medical records (EMR). Given the projected increase in the prevalence of T1DM, these robust data are critical for stakeholders to appropriately allocate resources for disease management.

\section{Methods}

\section{STUDY DESIGN AND DATA SOURCES}

This retrospective cohort study was conducted using IBM Watson MarketScan Commercial Claims and Medicare Supplemental data from January 1, 2011, to December 31, 2015, and Optum EMR and Optum integrated data (a database composed of patients with records from Optum's claims database and Optum's EMR database) from January 1, 2011, to December 31, 2016.

The MarketScan database consists of medical claims and drug dispensing data from employers and health plans of $>250$ million individuals insured by commercial and Medicare supplemental plans (including employees, their spouses, and dependents) since 1995.10,11 Optum's EMR database encompasses $>80$ million patients from all census regions, with at least 5 million patients from each region. Data are derived from more than 140,000 physicians at more than 600 hospitals and 6,500 clinics. Optum's integrated database combines information on demographic data, lab tests, costs, and medications dispensed with deterministically linked EMR and administrative claims for approximately 12 million patients across the United States.

Databases were selected for generalizability to the overall U.S commercially insured population, and multiple databases were analyzed to generate robust results and mitigate the inherent limitations found in each type of database. For example, cost data are only available from claims databases, but claims lack the rich clinical data present in EMR databases. 


\section{STUDY SAMPLE}

The databases were searched for patients with $\geq 1$ inpatient or outpatient claim with a primary or secondary diagnosis for T1DM (International Classification of Diseases, Ninth Revision, Clinical Modification [ICD-9-CM] codes 250. $\mathrm{x} 1$ and 250.x3 or International Classification of Diseases, Tenth Revision, Clinical Modification [ICD-10-CM] code E10) with continuous pre-index enrollment or EMR activity of $\geq 6$ months. To be eligible for inclusion, patients were required to have $\geq 1$ pharmacy claim for insulin or an insulin pump during the continuous enrollment period within \pm 90 days of the earliest claim date with evidence of a T1DM diagnosis (the index date).

Because many patients had T2DM, unspecified diabetes type, and T1DM diagnosis codes recorded, a required minimum proportion of days was established for the percentage of T1DM claims among all claims with a diabetes diagnosis using a modified version of an algorithm proposed by Dall et al. (2009). ${ }^{12}$ The required minimum proportion of days was least stringent among the youngest patients and most stringent among older patients, with the rationale that older patients would be more likely to have been diagnosed with insulin-dependent T2DM. The required minimum proportion of days for inclusion of T1DM diagnoses was calculated as the ratio of the sum of days with a T1DM diagnosis to the sum of days with any diabetes diagnosis. Patients were included if the proportion of days with a T1DM diagnosis was at least $50 \%$ for those aged $16-45$ years and at least $70 \%$ for those aged more than 45 years. All patients aged $<16$ years with any T1DM diagnosis were included.

Patients were excluded if they had secondary/gestational diabetes (identified using ICD-9-CM codes 249.xx and 648.8x; ICD-10-CM codes E08.x, E09.x, E13.x, and O24.x) at any time during the study period; if they used only long-acting insulin (i.e., no use of short- or intermediateacting insulin was identified in the patient's records); or had any use of sulfonylureas, thiazolidinediones, or combination drugs containing sulfonylureas or thiazolidinediones during the study period. A minimum of 6 months (and up to 12 months, if available) before the index date was defined as the baseline period, and the variable follow-up period began immediately after the index date and continued until the end of the study period, death, or end of enrollment, whichever occurred first. Information on enrollment is not available in the Optum EMR database; therefore, the last date of activity in the data was used as a proxy for enrollment.

\section{STUDY MEASURES}

Several demographic characteristics were assessed during the baseline period or at the index date (depending on the availability of measures in the database), including age, gender, race and ethnicity (available in the Optum databases only), geographic region, index year, and provider type. The clinical characteristics assessed during the baseline period included glycated hemoglobin (HbA1c) levels; Charlson Comorbidity Index (CCI) score ${ }^{13}$; selected comorbidities (including hypertension, hyperlipidemia, anxiety, depression, asthma, celiac disease, limited joint mobility, osteoporosis/ osteopenia, and autoimmune thyroid diseases); and diabetes-related complications (diabetic ketoacidosis, hypoglycemia, hyperglycemia, and microvascular [e.g., diabetic neuropathy, nephropathy, and retinopathy] and macrovascular complications [e.g., coronary heart disease, congestive heart failure, cerebrovascular disease, and peripheral vascular disease]) identified from inpatient and outpatient medical claims or records. The diagnosis codes used to identify all comorbidities are provided in Supplementary Table 1 (available in online article). Use of prescription medications, including types of insulin (i.e., rapid-acting, short/ intermediate-acting, long-acting, combinations, or administration procedures) and diabetes supplies (including use of insulin pumps and accessories, glucose test strips, CGM systems) during the baseline and follow-up periods was also assessed. Use of insulin pumps and glucose monitoring systems was identified using procedure codes (Supplementary Table 2, available in online article).

We evaluated all-cause and diabetes-related HCRU in all databases and costs (available in the MarketScan and Optum integrated database only) during the follow-up period across all health care settings (hospitalizations/ inpatient visits, outpatient visits, emergency department [ED] visits, and pharmacy). All-cause visits were defined as any inpatient or outpatient visit related to any diagnosis, while diabetes-related visits were inpatient or outpatient visits for which the primary diagnosis code was for T1DM or unspecified/T2DM (or discharge claim for an inpatient visit).

Costs included amounts paid by both health plans and patients for services, including medical and pharmacy costs. Diabetes-related pharmacy costs were defined as the costs associated with antidiabetic drugs of any type (insulin or other oral or injectable antidiabetic drugs), devices used for T1DM management that were purchased through a pharmacy, or blood glucose testing supplies. Costs for any procedures that were billed during an outpatient or inpatient visit, including those for insulin administration (e.g., if insulin was administered during a hospitalization), were included in the medical costs associated with that visit.

\section{STATISTICAL ANALYSIS}

Baseline characteristics were summarized descriptively for each database. Counts and proportions were used to 


\section{TABLE 1 Baseline Demographic and Clinical Characteristics}

\begin{tabular}{|c|c|c|c|}
\hline Characteristic/Category & $\begin{array}{l}\text { MarketScan } \\
(n=181,423)\end{array}$ & $\begin{array}{c}\text { Optum EMR } \\
\text { Database } \\
(n=84,759)\end{array}$ & $\begin{array}{c}\text { Optum } \\
\text { Integrated } \\
\text { Database } \\
(\mathbf{n}=\mathbf{8 , 9 4 8 )}\end{array}$ \\
\hline \multicolumn{4}{|l|}{ Age, in years, $n$ (\%) } \\
\hline 0 to $<6$ & $2,878 \quad(1.6)$ & $1,270 \quad(1.5)$ & 102 \\
\hline 6 to $<13$ & $16,585 \quad(9.1)$ & $6,418 \quad(7.6)$ & $508 \quad(5.7)$ \\
\hline 13 to $<18$ & $19,369(10.7)$ & $7,566 \quad(8.9)$ & $742 \quad(8.3)$ \\
\hline 18 to $<26$ & $29,245(16.1)$ & $13,242(15.6)$ & $1,355(15.1)$ \\
\hline 26 to $<50$ & $75,977 \quad(41.9)$ & $34,508 \quad(40.7)$ & $4,208 \quad(47.0)$ \\
\hline 50 to $<65$ & 31,671 (17.5) & $15,235(18.0)$ & $1,614(18.0)$ \\
\hline$\geq 65$ & $5,698 \quad(3.1)$ & $6,520 \quad(7.7)$ & $419 \quad(4.7)$ \\
\hline \multicolumn{4}{|l|}{ Gender, n (\%) } \\
\hline Male & $96,275 \quad(53.1)$ & $44,703 \quad(52.7)$ & $4,710(52.6)$ \\
\hline Female & $85,148 \quad(46.9)$ & $39,979 \quad(47.2)$ & $4,233 \quad(47.3)$ \\
\hline Unknown & $0 \quad(0.0)$ & $77 \quad(0.1)$ & $5 \quad(0.1)$ \\
\hline \multicolumn{4}{|l|}{ Index date, year, n (\%) } \\
\hline 2011 & $90,663 \quad(50.0)$ & $19,385(22.9)$ & $3,237 \quad(36.2)$ \\
\hline 2012 & $32,091 \quad(17.7)$ & $16,581 \quad(19.6)$ & $1,294(14.5)$ \\
\hline 2013 & $23,023 \quad(12.7)$ & $13,126(15.5)$ & $1,136(12.7)$ \\
\hline 2014 & $21,820(12.0)$ & $13,228(15.6)$ & 1,067 (11.9) \\
\hline 2015 & $13,826 \quad(7.6)$ & $12,066(14.2)$ & $1,015(11.3)$ \\
\hline 2016 & $0 \quad(0.0)$ & $10,373(12.2)$ & 1,199 (13.4) \\
\hline \multicolumn{4}{|l|}{ Race, n (\%) } \\
\hline White & $\mathrm{N} / \mathrm{A}$ & $70,067 \quad(82.7)$ & 7,517 (84.0) \\
\hline African American & $\mathrm{N} / \mathrm{A}$ & $6,540 \quad(7.7)$ & $368 \quad(4.1)$ \\
\hline Asian & $\mathrm{N} / \mathrm{A}$ & $626 \quad(0.7)$ & $53 \quad(0.6)$ \\
\hline Other/unknown & $\mathrm{N} / \mathrm{A}$ & $7,526 \quad(8.9)$ & $1,010(11.3)$ \\
\hline \multicolumn{4}{|l|}{ Ethnicity, n (\%) } \\
\hline Hispanic & $\mathrm{N} / \mathrm{A}$ & $3,528 \quad(4.2)$ & 334 \\
\hline Non-Hispanic & $\mathrm{N} / \mathrm{A}$ & $72,346(85.4)$ & 7,103 (79.4) \\
\hline Unknown & $\mathrm{N} / \mathrm{A}$ & $8,885(10.5)$ & $1,511(16.9)$ \\
\hline \multicolumn{4}{|l|}{ Geographic region, n (\%) } \\
\hline Northeast & $31,854 \quad(17.6)$ & $8,653(10.2)$ & $915(10.2)$ \\
\hline North Central/Midwest & $44,838 \quad(24.7)$ & $38,233 \quad(45.1)$ & $3,291 \quad(36.8)$ \\
\hline South & $67,235 \quad(37.1)$ & $27,132(32.0)$ & $3,483 \quad(38.9)$ \\
\hline West & $33,011(18.2)$ & $7,184 \quad(8.5)$ & $888 \quad(9.9)$ \\
\hline Unknown & $4,485 \quad(2.5)$ & $3,557 \quad(4.2)$ & $371 \quad(4.1)$ \\
\hline \multicolumn{4}{|l|}{ Provider type at index, $n$ (\%) } \\
\hline Endocrinologist & $35,495 \quad(19.6)$ & 26,735 & 2,623 \\
\hline Primary care physician & $47,533(26.2)$ & $18,333(21.6)$ & 2,056 \\
\hline
\end{tabular}

continued on next page describe categorical variables, while means, medians, standard deviations $(\mathrm{SD})$, and interquartile ranges (IQR) presenting the range from the 25 th to the 75 th percentile of values observed were used to describe continuous variables. Annualized HCRU and perpatient-per-month (PPPM) costs (including outpatient care, ED, inpatient care, and pharmacy) were assessed to account for differential lengths of baseline and follow-up. Costs were adjusted for inflation to 2018 U.S. dollars using the annual medical care component of the Consumer Price Index. The data were processed and analyzed using SAS statistical software version 9.4 (SAS Institute, Cary, NC).

\section{Results}

We identified 181,423 patients with T1DM in the MarketScan database, 84,759 patients in the Optum EMR database, and 8,948 patients in the Optum integrated database who met the study selection criteria (see Supplementary Figure 1, available in online article).

\section{BASELINE DEMOGRAPHIC AND CLINICAL CHARACTERISTICS}

Table 1 presents the baseline demographic and clinical characteristics of the cohorts. Across all databases, $52.6 \%-53.1 \%$ of the patients were male, and $40.7 \%-47 \%$ were aged $26-$ 49 years. Most patients were nonHispanic and White in the Optum EMR and integrated databases; race and ethnicity information are not reported in the MarketScan database. A relatively higher proportion of patients in the MarketScan (37.1\%) and Optum integrated databases $(38.9 \%)$ resided in the southern region, while a relatively higher proportion of patients (45.1\%) in the Optum EMR database resided in the Midwest region.

Because all patients had a recorded diagnosis of T1DM, the minimum CCI 


\section{TABLE 1}

\section{Baseline Dem
(continued)}

\begin{tabular}{|c|c|c|c|}
\hline Characteristic/Category & $\begin{array}{l}\text { MarketScan } \\
(n=181,423)\end{array}$ & $\begin{array}{c}\text { Optum EMR } \\
\text { Database } \\
(\mathrm{n}=\mathbf{8 4 , 7 5 9 )}\end{array}$ & $\begin{array}{c}\text { Optum } \\
\text { Integrated } \\
\text { Database } \\
(\mathbf{n = 8 , 9 4 8 )} \\
\end{array}$ \\
\hline \multicolumn{4}{|l|}{ Provider type at index, $\mathrm{n}(\%)$} \\
\hline Urgent care/emergency medicine/inpatient & $16,604 \quad(9.2)$ & $13,142(15.5)$ & $294 \quad(3.3)$ \\
\hline Other & $81,791(45.1)$ & $26,549(31.3)$ & $3,975(44.4)$ \\
\hline \multicolumn{4}{|l|}{ Baseline continuous enrollment, in months } \\
\hline Mean (SD) & $8.2 \quad(2.0)$ & $10.6 \quad(2.1)$ & $8.2(2.0)$ \\
\hline Median (IQR) & $7.5(6.0-12.0)$ & $12.0(6.0-12.0)$ & $7.5(6.0-12.0)$ \\
\hline Available baseline HbAlc measure, n (\%) & $6,703 \quad(3.7)$ & $54,906(64.8)$ & $1,340(15.0)$ \\
\hline \multicolumn{4}{|l|}{ Baseline HbAlc, n (\%) ${ }^{a}$} \\
\hline$<6.0 \%$ & $217 \quad(3.2)$ & $1,801 \quad(3.3)$ & $40 \quad(3.0)$ \\
\hline 6.0 to $<7.0 \%$ & $1,160(17.3)$ & $8,000(14.6)$ & $218(16.3)$ \\
\hline 7.0 to $<8.0 \%$ & $2,011(30.0)$ & $14,165(25.8)$ & $397(29.6)$ \\
\hline 8.0 to $<9.0 \%$ & $1,432(21.4)$ & $12,130(22.1)$ & $319(23.8)$ \\
\hline 9.0 to $<10.0 \%$ & $828(12.4)$ & 7,437 (13.5) & $183(13.7)$ \\
\hline 10.0 to $<11.0 \%$ & $433 \quad(6.5)$ & $4,286 \quad(7.8)$ & $80 \quad(6.0)$ \\
\hline 11.0 to $<12.0 \%$ & $277 \quad(4.1)$ & $2,652 \quad(4.8)$ & $48 \quad(3.6)$ \\
\hline 12.0 to $<13.0 \%$ & $144 \quad(2.1)$ & $1,765 \quad(3.2)$ & $25 \quad(1.9)$ \\
\hline 13.0 to $<14.0 \%$ & $107 \quad(1.6)$ & $1,117 \quad(2.0)$ & $10 \quad(0.7)$ \\
\hline$\geq 14.0$ & $94 \quad(1.4)$ & $1,553 \quad(2.8)$ & $20 \quad(1.5)$ \\
\hline \multicolumn{4}{|l|}{ CCI score, n (\%) } \\
\hline 1 & $132,483(73.0)$ & $60,995(72.0)$ & $6,188 \quad(69.2)$ \\
\hline 2 & $34,995 \quad(19.3)$ & $13,962(16.5)$ & $1,889(21.1)$ \\
\hline $3+$ & $13,945 \quad(7.7)$ & $9,802(11.6)$ & $871 \quad(9.7)$ \\
\hline \multicolumn{4}{|l|}{ Selected comorbidities, n (\%) } \\
\hline Any autoimmune thyroid disease & $26,530(14.6)$ & $13,448(15.9)$ & 1,707 (19.1) \\
\hline Hyperthyroidism & $1,650 \quad(0.9)$ & $856 \quad(1.0)$ & $119 \quad(1.3)$ \\
\hline Hypothyroidism & $23,024(12.7)$ & $11,888(14.0)$ & $1,505(16.8)$ \\
\hline Hashimoto's thyroiditis & $3,831 \quad(2.1)$ & $1,636 \quad(1.9)$ & $217 \quad(2.4)$ \\
\hline Hypertension & $35,083 \quad(19.3)$ & $21,807(25.7)$ & $2,294(25.6)$ \\
\hline Hyperlipidemia & $47,728 \quad(26.3)$ & $24,095(28.4)$ & $3,125 \quad(34.9)$ \\
\hline Depression & $11,936 \quad(6.6)$ & $7,423 \quad(8.8)$ & $755 \quad(8.4)$ \\
\hline Anxiety & $10,296 \quad(5.7)$ & $5,653 \quad(6.7)$ & $723 \quad(8.1)$ \\
\hline Celiac disease & $1,988 \quad(1.1)$ & $1,004 \quad(1.2)$ & $104 \quad(1.2)$ \\
\hline Asthma & $6,333 \quad(3.5)$ & $3,730 \quad(4.4)$ & $303 \quad(3.4)$ \\
\hline Limited joint mobility & $2,830 \quad(1.6)$ & $997 \quad(1.2)$ & $180 \quad(2.0)$ \\
\hline Osteoporosis/osteopenia & $3,794 \quad(2.1)$ & $2,249 \quad(2.7)$ & $253 \quad(2.8)$ \\
\hline
\end{tabular}

score was 1 ; about $27 \%-30 \%$ had a CCI score of 2 or more. The most commonly observed comorbidities during the baseline period were hyperlipidemia (range: 26.3\%-34.9\%), hypertension (range: 19.3\%-25.7\%), and autoimmune thyroid diseases (range: 14.6\%-19.1\%). When assessing patient history of the diabetes-related outcomes of interest, previous episodes of hyperglycemia, hypoglycemia, and diabetic ketoacidosis (DKA) were observed in 44.9\%-60.1\%, 9\%-11.4\%, and 6.6\%$7.4 \%$ of patients, respectively. The prevalence of microvascular complications ranged from $17.7 \%$ to $31.6 \%$. Data on HbA1c levels at baseline were available for only $3.7 \%$ of the patients from the MarketScan database, $64.8 \%$ of the patients from the Optum EMR database, and $15 \%$ of the patients from the Optum integrated data. Among patients with available HbA1c results, the mean baseline levels exceeded 8.0 across all 3 databases (range: 8.3-8.7).

Most patients used rapid-acting insulin during the baseline period (range: 63.8\%-81.5\%), followed by longacting insulin (range: $41 \%-42.9 \%$ ); the remaining patients had records for insulin use during the first 90 days of the follow-up period. Glucose test strips were used by $32.3 \%-65.4 \%$ of patients; insulin pumps were used by $3.2 \%-43.9 \%$; and continuous glucosemonitoring systems were used by $4.3 \%-15.6 \%$ of patients.

\section{BASELINE HCRU AND COST}

Overall, the annualized average (SD) number of all-cause outpatient visits during baseline ranged from 6 (8.9) to 13.6 (15.1); diabetes-related outpatient visits ranged from 1.9 (3.1) to 6.8 (6.5; Figure 1). Annualized average (SD) all-cause and diabetes-related ED visits during baseline ranged from 0.4 (1.1) to 0.5 (1.5) and $0.1(0.3)$ to 0.2 (0.7), respectively. The annualized average (SD) number of all-cause hospitalizations during baseline ranged from $0.2(0.8)$ to $0.4(1.8)$, while the 


\section{TABLE 1}

Baseline Dem
(continued)

\begin{tabular}{|c|c|c|c|}
\hline Characteristic/Category & $\begin{array}{l}\text { MarketScan } \\
(n=181,423)\end{array}$ & $\begin{array}{c}\text { Optum EMR } \\
\text { Database } \\
(\mathrm{n}=\mathbf{8 4 , 7 5 9 )}\end{array}$ & $\begin{array}{c}\text { Optum } \\
\text { Integrated } \\
\text { Database } \\
(\mathrm{n}=\mathbf{8 , 9 4 8 )}\end{array}$ \\
\hline \multicolumn{4}{|l|}{ Diabetic complications, n (\%) } \\
\hline Diabetic ketoacidosis & $13,401 \quad(7.4)$ & $6,192 \quad(7.3)$ & $593 \quad(6.6)$ \\
\hline Hyperglycemia & $109,056(60.1)$ & $38,015(44.9)$ & $4,699(52.5)$ \\
\hline Hypoglycemia & $20,561(11.3)$ & $7,665 \quad(9.0)$ & $1,024(11.4)$ \\
\hline Any microvascular complications & $39,667 \quad(21.9)$ & $14,971 \quad(17.7)$ & $2,830(31.6)$ \\
\hline Diabetic neuropathy & $14,064 \quad(7.8)$ & $7,234 \quad(8.5)$ & $1,478(16.5)$ \\
\hline Diabetic retinopathy & $26,624(14.7)$ & $8,065 \quad(9.5)$ & $1,584(17.7)$ \\
\hline Diabetic nephropathy & $8,438 \quad(4.7)$ & $4,130 \quad(4.9)$ & $1,140(12.7)$ \\
\hline Any macrovascular complications & 12,983 & $9,336 \quad(11.0)$ & 710 \\
\hline Coronary heart disease & 10,429 & 7,765 & $(6.5)$ \\
\hline Congestive heart failure & 1,717 & $1,900 \quad(2.2)$ & $(1.3)$ \\
\hline Cerebrovascular disease & 2,306 & 1,705 & $(1.4)$ \\
\hline Peripheral vascular disease & 2,454 & 1,939 & (1.6) \\
\hline \multicolumn{4}{|l|}{ Baseline insulin use ${ }^{b}$} \\
\hline Any insulin & $160,790 \quad(88.6)$ & $63,891 \quad(75.4)$ & $7,856 \quad(87.8)$ \\
\hline Rapid-acting insulin & $147,437 \quad(81.3)$ & $54,068 \quad(63.8)$ & $7,294 \quad(81.5)$ \\
\hline Short/intermediate-acting insulin & $8,582 \quad(4.7)$ & $10,797 \quad(12.7)$ & $(4.4)$ \\
\hline Long-acting insulin & $74,346 \quad(41.0)$ & $35,494 \quad(41.9)$ & $3,842 \quad(42.9)$ \\
\hline Insulin combination & $4,631 \quad(2.6)$ & 2,477 & (1.8) \\
\hline Insulin administration procedure ${ }^{c}$ & 3,518 & 5,628 & $(0.5)$ \\
\hline \multicolumn{4}{|l|}{ Other diabetic supplies and management } \\
\hline Insulin pump and accessories & $79,681 \quad(43.9)$ & 2,682 & $3,824 \quad(42.7)$ \\
\hline Glucose test strips & $100,659 \quad(55.5)$ & $27,350 \quad(32.3)$ & $5,848 \quad(65.4)$ \\
\hline Glucose monitoring system & $23,211 \quad(12.8)$ & 3,666 & $1,400 \quad(15.6)$ \\
\hline Diabetes self-care management ${ }^{d}$ & $67,684 \quad(37.3)$ & $23,596 \quad(27.8)$ & $3,587 \quad(40.1)$ \\
\hline \multicolumn{4}{|c|}{$\begin{array}{l}\text { aProportion of HbAlc categories were calculated using the number of patients with available HbAlc data } \\
\text { as the denominator. } \\
\text { 'All patients in the study received insulin, since those patients who did not have a claim for insulin during } \\
\text { the baseline period had I within } 90 \text { days of the index date. } \\
\text { Insulin administration procedures are an administration of insulin during a medical visit. } \\
\text { dDiabetes self-care management represents a set of procedure codes that providers can use to bill } \\
\text { for teaching patients how to check their blood glucose, take insulin, or perform similar activities. We } \\
\text { suspected that these codes may be a way to identify patients who were newly diagnosed with type } 1 \\
\text { diabetes. } \\
C C I=\text { Charlson Comorbidity Index; EMR=electronic medical record; HbAlc=glycated hemoglobin; } \\
I Q R=\text { interquartile range; } N / A=\text { not applicable; } S D=\text { standard deviation. }\end{array}$} \\
\hline
\end{tabular}

annualized average of diabetes-related hospitalizations ranged from 0.1 (0.5) to $0.1(0.7)$. The mean (SD) length of stay (LOS) associated with all-cause hospitalizations ranged from 3.4 (6.0) to 8.9 (131.1) days, and diabetes-related hospitalizations ranged from 2.4 (2.6) to 4.7 (15.5) days.
During baseline, total all-cause costs ranged from $\$ 1,254$ to $\$ 1,305$ PPPM, and diabetes-related total costs ranged from $\$ 636$ to $\$ 670$ PPPM (Figure 2). Across all databases, pharmacy costs contributed the most to total costs. Diabetes-related pharmacy costs contributed $46.9 \%$ (\$314)-55.3\% (\$352), and diabetesrelated outpatient costs accounted for $10.3 \%$ (\$69)-28.5\% (\$181) of the total diabetes-related PPPM costs across all databases. All-cause hospitalization costs accounted for $15.3 \%$ (\$192)-20.1\% (\$262) of the total PPPM costs, while diabetes-related hospitalization costs accounted for $11.9 \%$ (\$76)-16\% (\$107) of the total diabetes-related PPPM costs.

The median (IQR) diabetes-related cost per hospitalization ranged from $\$ 6,685 \quad(\$ 5,208-\$ 8,761)$ to $\$ 8,300$ (\$5,646-\$12,528; Table 2). The median (IQR) diabetes-related cost per ED visit ranged from \$1,041 (\$365-\$1,970) to $\$ 1,558$ (\$854-\$2,742). The median (IQR) cost per diabetes-related outpatient visit during baseline ranged from $\$ 137$ (\$89-\$208) to \$142 (\$101-\$347) across all databases (Table 2).

\section{HCRU AND COST DURING FOLLOW-UP}

The median (IQR) length of follow-up ranged from $16.8(0-54)$ months to 31.7 (0-66) months across all databases. The annualized average (SD) number of diabetes-related outpatient visits during the follow-up period ranged from 2.4 (3.9) to 7.0 (7.3; Figure 1); the corresponding annualized number of diabetes-related ED visits and diabetes-related hospitalizations ranged from $0.1(0.5)$ to 0.2 (1.6) and $0.1(0.5)$ to 0.3 (3.3), respectively. The mean (SD) LOS for diabetes-related hospitalizations ranged from 2.5 (2.8) to 8.4 (86.3) days across all databases.

During the follow-up period, total all-cause costs ranged from $\$ 1,482$ to $\$ 1,522$ PPPM (Figure 2). Overall, 


\section{FIGURE 1 Annualized Health Care Visits During Baseline and Follow-up}

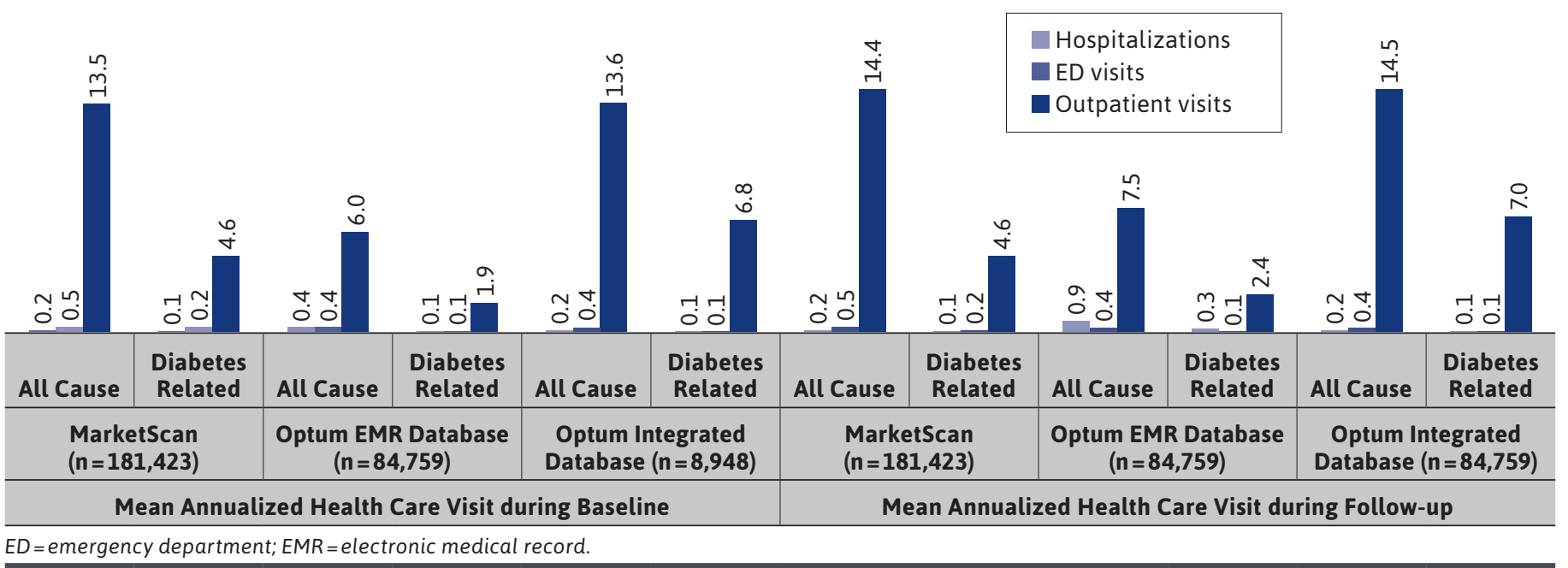

diabetes-related costs were approximately half of all-cause costs (\$733-\$780 PPPM). Pharmacy costs contributed substantially to the total all-cause and diabetes-related costs during the follow-up period and accounted for $55.3 \%$ (\$431)-61.1\% (\$448) of the total diabetes-related PPPM costs. Contributions of diabetes-related outpatient costs to the total diabetes-related PPPM costs were 9.4\% (\$73)-31.7\% (\$232).

Although hospitalizations were less commonly observed, all-cause hospitalizations comprised $11.5 \%$ (\$171)-13.9\% (\$212) of the total PPPM costs, and diabetes-related hospitalizations contributed $6.8 \%$ (\$53)-4.2\% (\$31) of the total diabetes-related PPPM costs. ED visits accounted for $4.1 \%$ (\$62)-4.7\% (\$70) of the total all-cause cost, and 1.6\% (\$12)$1.8 \%$ (\$14) of the total diabetes-related PPPM costs across all databases.

All-cause and diabetes-related costs per visit type during the follow-up period are presented in Table 3. The median (IQR) diabetes-related costs per hospitalization ranged from $\$ 6,548(\$ 4,911-\$ 8,886)$ to $\$ 8,439$ (\$5,609$\$ 12,657)$. Diabetes-related costs per ED visit were $\$ 972$ (\$327-\$1,898) to \$1,499 (\$802-\$2,729). Diabetes-related costs per outpatient visit ranged from $\$ 136(\$ 90-\$ 207)$ to $\$ 152$ (\$108-\$453) across all databases.

\section{Discussion}

In light of the expected increase in the prevalence of T1DM and current knowledge gaps in the literature regarding the health care and economic burdens faced by patients with T1DM, the results of this retrospective cohort study provide important insights into real-world HCRU and costs. The total all-cause costs incurred by patients with T1DM ranged from $\$ 1,482$ to $\$ 1,522$ PPPM in the study, and the total diabetes-related costs ranged from \$733 to \$780 PPPM. Routine pharmacy costs for prescription medications and supplies covered by the pharmacy benefit were the largest component of monthly costs $(55.3 \%-61.1 \%$ of the total diabetesrelated cost and $39.8 \%-41.6 \%$ of the total all-cause cost). While hospitalizations were relatively rare, they contributed nearly $11 \%-14 \%$ of the total monthly all-cause cost and $4 \%-$ $7 \%$ of the total monthly diabetes-related cost during followup. Similarly, ED visits, which were less commonly observed, contributed approximately $4 \%-5 \%$ of total all-cause costs and about $2 \%$ of diabetes-related monthly costs.

Our study found that ED visits and hospitalizations were relatively rare outcomes for patients with T1DM in a typical year. Because our study selection criteria required contact with the health care system for study inclusion (i.e., visits where diabetes diagnoses would be recorded), the patients in our study may have had more opportunities to be closely monitored by their health care providers than the overall T1DM population, which may have resulted in fewer hospitalizations or ED visits. Previous studies suggest that more outpatient visits, particularly visits to primary care, could improve outcomes and reduce health care spending through better preventive care, increased frequency of lifestyle counseling, and medication intensification. ${ }^{14-16}$ 


\section{FIGURE 2 Average Monthly Costs per Patient (PPPM) During Baseline and Follow-up}

\begin{tabular}{|c|c|c|c|c|c|c|c|c|}
\hline & All Cause & $\begin{array}{l}\text { Diabetes } \\
\text { Related }\end{array}$ & All Cause & $\begin{array}{l}\text { Diabetes } \\
\text { Related }\end{array}$ & All Cause & $\begin{array}{l}\text { Diabetes } \\
\text { Related }\end{array}$ & All Cause & $\begin{array}{l}\text { Diabetes } \\
\text { Related }\end{array}$ \\
\hline & \multicolumn{2}{|c|}{$\begin{array}{l}\text { MarketScan } \\
(n=181,423)\end{array}$} & \multicolumn{2}{|c|}{$\begin{array}{l}\text { Optum Integrated Database } \\
\qquad(\mathrm{n}=\mathbf{8 , 9 4 8 )}\end{array}$} & \multicolumn{2}{|c|}{$\begin{array}{l}\text { MarketScan } \\
(n=181,423)\end{array}$} & \multicolumn{2}{|c|}{$\begin{array}{l}\text { Optum Integrated Database } \\
\qquad(\mathrm{n}=\mathbf{8 , 9 4 8 )}\end{array}$} \\
\hline & \multicolumn{4}{|c|}{ Baseline Period, \$ } & \multicolumn{4}{|c|}{ Follow-up Period, \$ } \\
\hline Total cost & 1,305 & 670 & 1,254 & 636 & 1,522 & 780 & 1,482 & 733 \\
\hline - Hospitalization cost & 262 & 107 & 192 & 76 & 212 & 53 & 171 & 31 \\
\hline ED cost & 69 & 24 & 73 & 17 & 62 & 14 & 70 & 12 \\
\hline Outpatient visit cost & 297 & 69 & 398 & 181 & 349 & 73 & 483 & 232 \\
\hline Prescription cost & 448 & 314 & 475 & 352 & 605 & 431 & 616 & 448 \\
\hline Miscellaneous cost ${ }^{a}$ & 229 & 157 & 116 & 11 & 294 & 208 & 142 & 9 \\
\hline
\end{tabular}

Note: Cost could not be assessed in Optum EMR database.

a Miscellaneous cost included medical supplies, home care, laboratory, end-stage renal disease care, and ambulance, which did not fall into any of the other health care resource use categories.

$E D=$ emergency department; $E M R=$ electronic medical record; PPPM = per patient per month.

Furthermore, our study population appeared to be generally healthy and young, with $<10 \%$ of the patients aged $>65$ years, which may also be a reason that ED visits and hospitalizations were not observed more frequently. A report based on the Medical Expenditure Panel Survey and U.S.-based databases showed that among patients with T1DM, there is a positive relationship between age and hospitalization risk, with the highest proportion of hospitalizations reported for those aged $>65$ years. ${ }^{17}$ Similarly, a cross-sectional study conducted in Mexico in 2016 reported that adult T1DM patients with more chronic complications have higher rates of ED visits and hospitalizations. ${ }^{18}$ These findings may suggest the importance of better diabetes management via good glycemic control in this patient population.

Our findings that diabetes-related costs totaled approximately $\$ 800$ PPPM were similar to the total annual costs of $\$ 9,600$ attributed to diabetes reported by the American Diabetes Association in 2017; however, that study combined patients with T1DM and T2DM. ${ }^{5}$ We found that all-cause and diabetes-related pharmacy costs contributed the most to the total costs of T1DM care.
Our findings are consistent with a retrospective, crosssectional, real-world study that used administrative claims data from the HealthCore Integrated Research Database from 2007 to 2014 to assess all-cause and diabetes-attributable HCRU and costs of T1DM. ${ }^{8}$ This study found that pharmacy prescriptions and outpatient visits were the major drivers of increasing costs over time. Similar findings were reported in another retrospective, cross-sectional, multicenter study conducted in Brazil between 2008 and 2010. ${ }^{7}$ All-cause total direct costs associated with T1DM were high and mainly associated with drug treatment and supplies for insulin administration and self-monitoring of blood glucose.

These findings suggest that efforts to reduce the costs associated with T1DM will need to include management of costs associated with insulin, supplies for insulin administration, and devices for monitoring blood glucose and cannot only focus on the avoidance of costly but rare outcomes, such as hospitalizations. The development of biosimilar insulins is expected to stimulate competition within the market and reduce the cost of insulin for patients and payers. ${ }^{19}$ 


\section{TABLE 2}

\section{Baseline Health Care Costs per Visit Among Patients with T1DM}

\begin{tabular}{|c|c|c|c|c|}
\hline \multirow[b]{2}{*}{$\begin{array}{l}\text { Health Care } \\
\text { Setting }\end{array}$} & \multicolumn{2}{|c|}{$\begin{array}{c}\text { MarketScan } \\
(n=181,423), \$\end{array}$} & \multicolumn{2}{|c|}{$\begin{array}{l}\text { Optum Integrated Database } \\
(n=8,948), \$\end{array}$} \\
\hline & $\begin{array}{c}\text { All-Cause } \\
\text { Cost per Visit }\end{array}$ & $\begin{array}{c}\text { Diabetes-Related } \\
\text { Cost per Visit }\end{array}$ & $\begin{array}{l}\text { All-Cause } \\
\text { Cost per Visit }\end{array}$ & $\begin{array}{c}\text { Diabetes-Related } \\
\text { Cost per Visit }\end{array}$ \\
\hline \multicolumn{5}{|c|}{ Hospitalizations } \\
\hline Mean (SD) & $\begin{array}{l}16,509 \\
(44,109)\end{array}$ & $\begin{array}{l}11,091 \\
(15,763)\end{array}$ & $\begin{array}{l}13,023 \\
(22,237)\end{array}$ & $\begin{array}{c}9,195 \\
(12,665)\end{array}$ \\
\hline Median (IQR) & $\begin{array}{c}9,422 \\
(6,055-15,900)\end{array}$ & $\begin{array}{c}8,300 \\
(5,646-12,528)\end{array}$ & $\begin{array}{c}7,568 \\
(5,439-12,663)\end{array}$ & $\begin{array}{c}6,685 \\
(5,208-8,761)\end{array}$ \\
\hline \multicolumn{5}{|l|}{ ED visits } \\
\hline Mean (SD) & $\begin{array}{l}1,603 \\
(3,035)\end{array}$ & $\begin{array}{l}1,504 \\
(2,147)\end{array}$ & $\begin{array}{c}2,344 \\
(2,973)\end{array}$ & $\begin{array}{l}2,217 \\
(2,322)\end{array}$ \\
\hline Median (IQR) & $\begin{array}{c}1,070 \\
(459-1,974) \\
\end{array}$ & $\begin{array}{c}1,041 \\
(365-1,970)\end{array}$ & $\begin{array}{c}1,567 \\
(848-2,846) \\
\end{array}$ & $\begin{array}{c}1,558 \\
(854-2,742) \\
\end{array}$ \\
\hline \multicolumn{5}{|c|}{ Outpatient visits } \\
\hline Mean (SD) & $\begin{array}{c}279 \\
(2,682)\end{array}$ & $\begin{array}{l}194 \\
(660) \\
\end{array}$ & $\begin{array}{c}378 \\
(3,486)\end{array}$ & $\begin{array}{l}352 \\
(964)\end{array}$ \\
\hline Median (IQR) & $\begin{array}{c}126 \\
(79-212)\end{array}$ & $\begin{array}{c}137 \\
(89-208)\end{array}$ & $\begin{array}{c}120 \\
(82-239)\end{array}$ & $\begin{array}{c}142 \\
(101-347)\end{array}$ \\
\hline
\end{tabular}

Note: Cost could not be assessed in Optum EMR database.

$E D=$ emergency department; $I Q R=$ interquartile range; $S D$ = standard deviation

While insulin use and regular visits to health care providers are critical components of care among patients with T1DM, there is a continued need to reduce complications that could result in hospitalizations or ED visits. With the advancement of newer technologies that aim to better control diabetes, it may be possible to substantially reduce costs by preventing certain hospitalizations and ED visits. For example, patients using CGM can identify their "time-in-range" (the percentage of time that blood glucose levels remain in the target range), unlike those who self-monitor their glucose levels; CGM is now recommended by national guidelines for the management of T1DM. ${ }^{20-22} \mathrm{~A}$ randomized controlled trial in pediatric and adult patients with T1DM conducted by JDRF showed a $46 \%$ reduction in the incidence of severe hypoglycemia with the use of real-time continuous glucose monitoring. In our present study, use of CGM increased by $31.3 \%$ during the follow-up period (data not shown), and it is likely that the percentage of patients with T1DM using CGM continued to increase after the study period ended. Thus, further studies are needed to assess this effect on health care costs in later years.

While hospitalizations and ED visits were less commonly observed in our cohort, the median cost per visit was substantial. Diabetes-related costs per hospitalization ranged from $\$ 6,548$ to $\$ 8,439$, and diabetes-related costs per ED visit ranged from $\$ 972$ to $\$ 1,499$. Studies suggest that most of the ED visits and hospitalizations among these patients are attributed to acute diabetes complications, such as DKA, hyperglycemia, and hypoglycemia events. ${ }^{18}$ A cross-sectional study conducted in 2016 among T1DM patients aged $\geq 18$ years in Mexico reported that approximately $25 \%$ of the hospitalizations among these patients were due to hyperglycemia; $22 \%$ were due to DKA; $14 \%$ were due to hypoglycemia; and about $29 \%$ of patients had ED visits due to hyperglycemia and $27 \%$ due to hypoglycemia. ${ }^{18}$ While we did not assess the specific costs of these events in our study, efforts to improve glycemic control should reduce them. Studies conducted in patients with diabetes (T1DM and T2DM) found a sustained reduction in HbA1c levels among adult patients is associated with significant cost savings. ${ }^{23-26}$ A cohort study conducted among patients with both diabetes types showed that improvement in HbA1c levels $\geq 1 \%$ could potentially save between $\$ 685$ and $\$ 950$ per year, mostly attributed to reduced hospital admissions and outpatient visits. ${ }^{26}$ Better glucose control could reduce the risk of such complications and, thus, could potentially reduce hospitalizations and ED visits and subsequent economic burden associated with T1DM.

\section{LIMITATIONS}

This study has certain limitations inherent to EMR and claims-based analyses that must be considered when interpreting the results. Diagnoses and procedures recorded in claims data are primarily intended for billing purposes and may be subject to upcoding and data entry errors. ${ }^{27,28}$ Given that the presence of comorbidities was determined using inpatient/ outpatient claims or records, conditions that did not require medical attention were not captured. Thus, it is likely that the prevalence of certain comorbidities and complications (e.g., hypoglycemia and hyperglycemia) may have been underestimated in our study. However, as self-treated events are not associated with care from medical providers (and therefore do not incur additional medical costs), 


\section{TABLE 3}

\begin{tabular}{|c|c|c|c|c|}
\hline \multirow[b]{2}{*}{$\begin{array}{l}\text { Health Care } \\
\text { Setting }\end{array}$} & \multicolumn{2}{|c|}{$\begin{array}{c}\text { MarketScan } \\
(n=181,423), \$\end{array}$} & \multicolumn{2}{|c|}{$\begin{array}{l}\text { Optum Integrated Database } \\
(n=8,948), \$\end{array}$} \\
\hline & $\begin{array}{l}\text { All-Cause } \\
\text { Cost per Visit }\end{array}$ & $\begin{array}{c}\text { Diabetes-Related } \\
\text { Cost per Visit }\end{array}$ & $\begin{array}{c}\text { All-Cause } \\
\text { Cost per Visit }\end{array}$ & $\begin{array}{c}\text { Diabetes-Related } \\
\text { Cost per Visit }\end{array}$ \\
\hline \multicolumn{5}{|l|}{ Hospitalizations } \\
\hline Mean (SD) & $\begin{array}{c}20,646 \\
(51,096)\end{array}$ & $\begin{array}{l}13,402 \\
(29,001)\end{array}$ & $\begin{array}{l}15,027 \\
(27,383)\end{array}$ & $\begin{array}{c}8,731 \\
(11,096) \\
\end{array}$ \\
\hline Median (IQR) & $\begin{array}{c}10,927 \\
(6,546-20,047)\end{array}$ & $\begin{array}{c}8,439 \\
(5,609-12,657) \\
\end{array}$ & $\begin{array}{c}8,555 \\
(5,019-16,101) \\
\end{array}$ & $\begin{array}{c}6,548 \\
(4,911-8,886)\end{array}$ \\
\hline \multicolumn{5}{|l|}{ ED visits } \\
\hline Mean (SD) & $\begin{array}{c}1,672 \\
(3,931) \\
\end{array}$ & $\begin{array}{c}1,438 \\
(2,714)\end{array}$ & $\begin{array}{c}2,606 \\
(4,135) \\
\end{array}$ & $\begin{array}{c}2,259 \\
(3,232)\end{array}$ \\
\hline Median (IQR) & $\begin{array}{c}1,112 \\
(470-2,060)\end{array}$ & $\begin{array}{c}972 \\
(327-1,898) \\
\end{array}$ & $\begin{array}{c}1,676 \\
(919-3,073) \\
\end{array}$ & $\begin{array}{c}1,499 \\
(802-2,729) \\
\end{array}$ \\
\hline \multicolumn{5}{|c|}{ Outpatient visits } \\
\hline Mean (SD) & $\begin{array}{c}288 \\
(5,317)\end{array}$ & $\begin{array}{l}191 \\
(755)\end{array}$ & $\begin{array}{c}394 \\
(4,425)\end{array}$ & $\begin{array}{c}387 \\
(1,130)\end{array}$ \\
\hline Median (IQR) & $\begin{array}{c}125 \\
(77-211)\end{array}$ & $\begin{array}{c}136 \\
(90-207)\end{array}$ & $\begin{array}{c}120 \\
(82-273)\end{array}$ & $\begin{array}{c}152 \\
(108-453)\end{array}$ \\
\hline
\end{tabular}

Note: Cost could not be assessed in Optum EMR database.

$E D=$ emergency department; $I Q R=$ interquartile range; $S D=$ standard deviation . resource utilization and costs are not underestimated from this limitation.

Pharmacy claims only indicate receipt of a medication from a pharmacy; thus, use of the medication is assumed in claims data, while medication prescriptions from EMR data may not be filled. For similar reasons, we may have underestimated the use of test strips and insulin pumps by relying on claims or prescriptions records.

Furthermore, while laboratory measures, such as HbA1c levels, are useful indicators of diabetes severity, they are available for limited proportions of patients in claims databases, and target HbA1c levels are not available. Cost data are not available in the Optum EMR database, and indirect costs, such as lost work productivity attributed to short-term/long-term morbidity and caregiver burden, are not available in claims or EMR databases and could not be assessed. Since patients with unspecified diabetes diagnoses were included in the study after meeting other study criteria, claims with any diagnosis code for diabetes were identified as having diabetes-related costs.

In a sensitivity analysis, T1DMrelated costs (restricted to those claims with a T1DM diagnosis) were also analyzed; the results were similar to the diabetes-related costs presented in our study and are therefore not reported. Finally, the generalizability of the study results may be limited to commercially insured patients in the United States (claims data) and/or those with regular access to care (EMR data).

Despite these limitations, our study leverages the large sample sizes of patients available in the EMR and claims databases used; the similarity of results across these 3 databases provides evidence for their robustness. Limitations of the study have been mitigated to some extent by using EMR and claims data as complementary sources of information.

\section{Conclusions}

In this retrospective analysis of data from 3 U.S. data sources over 5 years, overall medical costs averaged approximately $\$ 1,500$ per patient per month, and diabetes-related costs totaled nearly $\$ 800$ per patient per month for adult and pediatric patients with T1DM. Pharmacy costs contributed to over half of the monthly diabetes-related costs for patients with T1DM. While relatively uncommon, hospitalizations and ED visits were expensive; efforts are still needed to reduce these potentially avoidable events. Further research can help to understand the risk factors associated with hospitalizations and ED visits, as well as indirect costs associated with T1DM management.

\section{DISCLOSURES}

JDRF International provided funding for this project and manuscript. JDRF International also contracted with Evidera, a research and consulting firm for the biopharma industry, for its participation in the project and in the development of this manuscript. The Leona M. and Harry B. Helmsley Charitable Trust provided JDRF International with funding.

Simeone, Shah, and Ganz are employed by Evidera and do not receive any payment or honoraria directly from Evidera's clients. LeGrand is an employee of JDRF International. Bushman was employed by JDRF International during the conduct of the study and development of this manuscript. Sullivan and Koralova are employees of The Leona M. and Harry B. Helmsley Charitable Trust. 


\section{ACKNOWLEDGMENTS}

The authors thank Michael Grossi and Vibha Shukla of Evidera for their help editing and formatting this manuscript; Catherine Mercaldi of Evidera for providing programming support; and Roy Beck and Kellee Miller of the Jaeb Center for Health Research for their review of the data and manuscript.

\section{REFERENCES}

1. American Diabetes Association.

Diagnosis and classification of diabetes mellitus. Diabetes Care. 2009;32(Suppl 1): S62-67.

\section{Maahs DM, West NA, Lawrence JM,} Mayer-Davis EJ. Epidemiology of type 1 diabetes. Endocrinol Metab Clin North Am. 2010;39(3):481-97.

3. Centers for Disease Control and Prevention. National Diabetes Statistics Report, 2020. Accessed October 13, 2020. https://www.cdc.gov/diabetes/pdfs/ data/statistics/national-diabetes-statistics-report.pdf

4. Imperatore G, Boyle JP, Thompson TJ, et al. Projections of type 1 and type 2 diabetes burden in the U.S. population aged $<20$ years through 2050: dynamic modeling of incidence, mortality, and population growth. Diabetes Care. 2012;35(12):2515-20.

5. American Diabetes Association.

Economic costs of diabetes in the U.S. in 2017. Diabetes Care. 2018;41(5):917-28.

6. American Association of Clinical Endocrinologists. The burden of type 1 diabetes. 2019. Accessed October 13, 2020. https://pro.aace.com/disease-stateresources/diabetes/depth-information/ burden-type-1-diabetes

7. Cobas RA, Ferraz MB, Matheus AS, et al. The cost of type 1 diabetes: a nationwide multicentre study in Brazil. Bull World Health Organ. 2013;91(6):434-40.
8. Willey VJ, Kong S, Wu B, et al. Estimating the real-world cost of diabetes mellitus in the United States during an 8-year period using 2 cost methodologies. Am Health Drug Benefits. 2018;11(6):310-18.

9. Tao B, Pietropaolo M, Atkinson M, Schatz D, Taylor D. Estimating the cost of type 1 diabetes in the U.S.: a propensity score matching method. PLoS One. 2010;5(7):e11501.

10. IBM Watson Health. Data brochure. IBM MarketScan research databases for life sciences researchers. July 2020. Accessed October 13, 2020. https://www. ibm.com/downloads/cas/OWZWJOQO

11. IBM Watson Health. Solution brief. IBM MarketScan research databases: data for government health and human services research. 2019. Accessed October 13, 2020. https://www.ibm.com/downloads/ cas/JMPKEDA5

12. Dall TM, Mann SE, Zhang Y, et al. Distinguishing the economic costs associated with type 1 and type 2 diabetes. Popul Health Manag. 2009;12(2):103-10.

13. Quan H, Sundararajan V, Halfon P, et al. Coding algorithms for defining comorbidities in ICD-9-CM and ICD-10 administrative data. Med Care. 2005;43(11):1130-39.

14. Morrison F, Shubina M, Goldberg SI, Turchin A. Performance of primary care physicians and other providers on key process measures in the treatment of diabetes. Diabetes Care. 2013;36(5):1147-52.

15. Mostashari F, Sanghavi D, McClellan M. Health reform and physician-led accountable care: the paradox of primary care physician leadership. JAMA. 2014;311(18):1855-56.

16. Starfield B, Shi L, Macinko J. Contribution of primary care to health systems and health. Milbank Q. 2005;83(3):457-502.

17. McEwen LN, Herman WH. Health care utilization and costs of diabetes. In: Cowie CC, Casagrande SS, Menke A, et al., eds. Diabetes in America. 3rd ed. National Institutes of Health; 2017.
18. Doubova SV, Ferreira-Hermosillo A, Perez-Cuevas R, Barsoe C, GryzbowskiGainza E, Valencia JE. Socio-demographic and clinical characteristics of type 1 diabetes patients associated with emergency room visits and hospitalizations in Mexico. BMC Health Serv Res. 2018;18(1):602.

19. Aideed $\mathrm{H}$. Will biosimilars solve the insulin cost-conundrum in the U.S.? Biosimilar Development Newsletter. May 28, 2019. Accessed October 13, 2020. https://www.biosimilardevelopment. com/doc/will-biosimilars-solve-the-insulin-cost-conundrum-in-the-u-s-0001

20. American Diabetes A. 7. Diabetes technology: standards of medical care in diabetes-2020. Diabetes Care. 2020;43(Suppl 1):S77-S88.

21. Handelsman Y, Bloomgarden ZT, Grunberger $\mathrm{G}$, et al. American association of clinical endocrinologists and american college of endocrinology - clinical practice guidelines for developing a diabetes mellitus comprehensive care plan - 2015. Endocr Pract. 2015;(21 Suppl 1):1-87.

22. Peters AL, Ahmann AJ, Battelino T, et al. Diabetes technology-continuous subcutaneous insulin infusion therapy and continuous glucose monitoring in adults: an endocrine society clinical practice guideline. J Clin Endocrinol Metab. 2016;101(11):3922-37.

23. Bansal M, Shah M, Reilly B, Willman S, Gill M, Kaufman FR. Impact of reducing glycated hemoglobin on healthcare costs among a population with uncontrolled diabetes. Appl Health Econ Health Policy. 2018;16(5):675-84.

24. Baxter M, Hudson R, Mahon J, et al. Estimating the impact of better management of glycaemic control in adults with Type 1 and Type 2 diabetes on the number of clinical complications and the associated financial benefit. Diabet Med. 2016;33(11):1575-81.

25. McEwan P, Bennett H, Bolin K, Evans M, Bergenheim K. Assessing the economic value of maintained improvements in type 1 diabetes management, in terms of HbA1c, weight and hypoglycaemic event incidence. Diabet Med. 2018;35(5):557-66. 
26. Wagner EH, Sandhu N, Newton KM, McCulloch DK, Ramsey SD, Grothaus LC. Effect of improved glycemic control on health care costs and utilization. JAMA. 2001;285(2):182-89.
27. Centers for Disease Control and Prevention. Vision and Eye Health Surveillance System (VEHSS): administrative claims databases. 2018. Accessed October 13, 2020. https://www.cdc.gov/ visionhealth/vehss/data/claims/index.html
28. Johnson EK, Nelson CP. Values and pitfalls of the use of administrative databases for outcomes assessment. J Urol. 2013;190(1):17-18. 